\title{
Functionalized ensembles of nanoelectrodes as affinity biosensors for DNA hybridization detection
}

\author{
Morena Silvestrini ${ }^{\mathrm{a}}$, Ljiljana Fruk ${ }^{\mathrm{b}}$, Paolo Ugo ${ }^{\mathrm{a}, *}$ \\ a Department of Molecular Sciences and Nanosystems, University Ca' Foscari of Venice, Santa Marta 2137, 30123 Venice, Italy \\ ${ }^{\mathrm{b}}$ Karlsruhe Institute of Technology, DFG-Centre for Functional Nanostructures, Wolfgang Gaede Str. 1, 76131 Karlsruhe, Germany
}

\section{A R T I C L E I N F O}

Available online 3 August 2012

Keywords:

Nanoelectrodes

Ensemble

Biosensors

Polycarbonate

DNA

\begin{abstract}
A B S T R A C T
A novel electrochemical biosensor for DNA hybridization detection based on nanoelectrode ensembles (NEEs) is presented. NEEs are prepared by electroless deposition of gold into the pores of a templating track-etched polycarbonate (PC) membrane. The wide surface of the templating membrane surrounding the nanoelectrodes is exploited to bind the capture DNA probes via amide coupling with the carboxylic groups present on the PC surface. The probes are then hybridized with the complementary target labelled with glucose oxidase $\left(\mathrm{GO}_{x}\right)$. The occurrence of the hybridization event is detected by adding, to the supporting electrolyte, excess glucose as the substrate and the (ferrocenylmethyl) trimethylammonium cation $\left(\mathrm{FA}^{+}\right)$as suitable redox mediator. In the case of positive hybridization, an electrocatalytic current is detected. In the proposed sensor, the biorecognition event and signal transduction occur in different but neighbouring sites, i.e., the PC surface and the nanoelectrodes, respectively; these sites are separated albeit in close proximity on a nanometer scale. Finally, the possibility to activate the PC surface by treatment with permanganate is demonstrated and the analytical performances of biosensors prepared with $\mathrm{KMnO}_{4}$-treated NEEs and native NEEs are compared and critically evaluated. The proposed biosensor displays high selectivity and sensitivity, with the capability to detect few picomoles of target DNA.
\end{abstract}

(c) 2012 Elsevier B.V. All rights reserved.

\section{Introduction}

The development of electrochemical sensors for DNA detection is widely documented in the recent literature (Kerman et al., 2004; Lucarelli et al., 2004; Hvastkovs and Buttry, 2010; Pedrero et al., 2011). Such sensors are based on the immobilization of an oligonucleotide probe containing the nucleotide sequence of interest onto the surface of the transducer. In this way, due to the presence of the complementary sequence in the sample, the hybridization process takes place directly on the electrode surface, easing the detection.

Different approaches have been employed to enable electrochemical detection of the hybridization event, many of them requiring the use of electrochemical labels such as redox or enzyme labels (Carpini et al., 2004; Levine et al., 2009; Tang et al., 2009) or intercalating redox probes (Girousi and Kinigopoulou, 2010; Wei et al., 2011), or by enabling the label-free detection (Kerman et al., 2003). Recently, the DNA hybridization event was detected by binding the capture DNA onto the surface of complex 3D-structures, such as carbon nanotubes (Abdullin et al., 2007; Li et al., 2003) or

\footnotetext{
* Corresponding author. Tel.: +39041234 8503: fax: +390412348594.

E-mail address: ugo@unive.it (P. Ugo).
}

metal nanowires (Lapierre-Devlin et al., 2005). In the latter work, arrayed gold nanowires obtained by partial etching of the polycarbonate surface of nanoelectrode ensembles (NEEs) with oxygen plasma were exploited for the immobilization of the biorecognition layer onto the gold surface of the nanoelectrodes. NEEs are random arrays of nanoelectrodes typically prepared by electroless deposition of gold electrode elements within the pores of a microporous polycarbonate (PC) membrane (Menon and Martin, 1995; Ugo and Moretto, 2007). The diameter and length of the pores in the template determines the geometrical characteristics of the metal nanostructure with radii, usually, of approximately $30 \mathrm{~nm}$ and average distance between the nanoelectrodes around $200 \mathrm{~nm}$. For such NEEs the diffusion hemispheres at individual nanoelectrodes overlap and the so-called total overlap diffusion regime, holds. The voltammetric peak current recorded under such conditions is proportional to the overall geometric area of the ensemble $\left(A_{\text {geom }}\right)$, while the background capacitive current (that is the main component of the noise) is proportional only to the active area $\left(A_{\text {act }}\right)$. Because of NEEs' geometrical characteristics, the ratio $A_{\text {geom }} /$ $A_{\text {act }}$ is as high as $10^{2}-10^{3}$, so that signal/background current ratios are enhanced and detection limits improved 2-3 order of magnitudes (Brunetti et al., 2000; Ugo et al., 1996). Physical (Yu et al., 2003) or chemical (De Leo et al., 2007; Krishnamoorthy and Zoski, 2005) etching allows the controlled removal of the PC which 
surrounds the nanoelectrodes so exposing partially or totally (depending on the etching time) the gold nanowires which compose the ensemble. This allows one to increase $A_{\text {act }}$ so that larger amounts of biorecognition molecules can be bound on the exposed gold surface. However, such a treatment can cause a not negligible drawback, that is the increase of the double-layer charging current (background noise). It was demonstrated (De Leo et al., 2007) that the etching of NEEs leads indeed to a significant decrease in signal to background current ratio (De Leo et al., 2007), so losing one of the advantages of NEEs.

In order to keep the geometric features intact and the signal/ noise ratio at the maximum, in the present research we developed an alternative approach which is based on exploiting for functionalization/biorecognition purposes the wide polycarbonate surface which surrounds the nanoelectrodes, instead of the nanoelectrodes themselves (Gasparac et al., 2004; Lapierre-Devlin et al., 2005).

Polycarbonate is indeed one of the most used polymeric platforms for the fabrication of bioanalytical sensors for protein or DNA detection (Li et al., 2007; Morais et al., 2006, 2009; Rucker et al., 2005; Wang and $\mathrm{Li}, 2007)$; moreover, it is commonly employed as an insulator in the preparation of ensembles and arrays of nanoelectrodes (De Leo et al., 2007; Krishnamoorthy and Zoski, 2005; Menon and Martin, 1995; Moretto et al., 2011). In a recent paper, the polymeric surface of NEEs was employed in our laboratory for the immobilization of antibodies in an electrochemical immunosensor for the detection of the receptor protein HER2 (Mucelli et al., 2008). In that case, the capture antibody trastuzumab was immobilized by direct adsorption (without any pre-treatment) onto the PC surface, which surrounds the nanoelectrodes, leaving the electrodes free for electrochemical transduction. The biosensing capabilities of such NEEs were tested in tumor lysates allowing the detection of HER2 down to $40 \mathrm{pg} / \mu \mathrm{L}$. In some cases, aspecific adsorption of proteins on the gold nanodisks was observed, limiting the electrochemical signal and, consequently, the detection efficiency. In order to overcome this problem, the possibility to protect the nanoelectrodes with self-assembled monolayers of thiols was studied (Silvestrini et al., 2011). Preliminary attempts performed by us, indicated that for the immobilization of polynucleotides the procedure previously used for proteins, was unsuccessful. This motivated us to perform the present study aimed at developing immobilization procedures specifically devoted at binding DNA probes onto the PC of NEEs.

We demonstrate here that capture oligonucleotide probes can be immobilized on the PC of NEEs by grafting on the $-\mathrm{COOH}$ groups naturally present on the PC surface or, eventually, increased in number by a chemical oxidation process. Finally, the hybridization with complementary DNA strand was detected by labeling the target with glucose oxidase (operating in the presence of glucose and a suitable redox mediator) so proving the functionality of the NEE-based hybridization sensor.

\section{Experimental}

\subsection{Materials and apparatus}

Potassium permanganate $\left(\mathrm{KMnO}_{4}\right)$ was purchased from Carlo Erba. Thionin acetate (THA), $N$-ethyl- $N^{\prime}$-(3-dimethylaminopropyl) carbodiimide hydrochloride (EDC), $\mathrm{N}$-hydroxysulfosuccinimide sodium salt (sulfo-NHS), ethanolamine and glucose oxidase $\left(\mathrm{GO}_{x}\right)$ from Aspergillus niger were from Sigma-Aldrich. The salt (ferrocenylmethyl) trimethylammonium hexafluorophosphate $\left(\mathrm{FA}^{+} \mathrm{PF}_{6}^{-}\right)$was prepared by metathesis of the (ferrocenylmethyl) trimethylammonium iodide (Alfa Aesar) with an excess of potassium hexafluorophosphate 99\% (Alfa Aesar) (Lombardo and Bieber, 1983). The mixing of the aqueous solutions containing the two salts, in an ice cooling bath, allowed the formation of a yellow precipitate that was then filtrated, rinsed 5 times with cool water and finally dried in a vacuum oven.

Amino-end DNA (acD1 and acD2) and thiolated DNA (SHD1) were purchased from Sigma-Aldrich with the following sequences:

acD1: [AmC6T]CTTATCGCTTTATGACCGGACC

acD2: [Am5T]TTGTTATACGCC

SHD1: [ThiolC6]GGTCCGGTCATAAAGCGATAAG

Stock solutions of oligonucleotides $(100 \mu \mathrm{M})$ were prepared in $50 \mathrm{mM}$ Tris, $100 \mathrm{mM} \mathrm{NaCl}, 1 \mathrm{mM}$ EDTA (TE buffer, $\mathrm{pH}$ 7.4) and kept frozen until use. Dithiothreitol (DTT) was from AppliChem. $\mathrm{N}$-2hydroxyethyl piperazine-N'-2-ethanesulfonic acid (HEPES) $\geq 99.5 \%$, p.a. was purchased from Carl ROTH. The cross-linker sulfosuccinimidyl 4-[N-maleimidomethyl]-cyclohexane-1-carboxylate was purchased from Sigma-Aldrich. Purified water was obtained using MilliRo plus Milli-Q (Millipore) water purification system. All other chemicals were reagent grade.

Track-etch polycarbonate (PC) membrane filters were obtained from SPI-pore ${ }^{\mathrm{TM}}$ with nominal pore diameter of $30 \mathrm{~nm}$, average pore density of $6 \times 10^{8}$ pores $\mathrm{cm}^{-2}$ and coated with polyvinylpyrrolidone (PVP) by the producer.

All electrochemical measurements were carried out at room temperature with a PalmSens potentiostat controlled via personal computer by its own software, using a three-electrode singlecompartment cell equipped with a platinum counter electrode and an $\mathrm{Ag} / \mathrm{AgCl}$ ( $\mathrm{KCl}$ saturated) reference electrode, to which all reported potential values are referred. Fluorescence measurements were carried out with a Varian, Cary Eclipse Fluorescence Spectrophotometer. NAP ${ }^{\mathrm{TM}}-5$ and $\mathrm{NAP}^{\mathrm{TM}}-10$ columns prepacked with Sephadex ${ }^{\mathrm{TM}}$ G-25 DNA Grade were from GE Healthcare. Ultrafiltration devices (Vivaspin6 $30000 \mathrm{MWCO}$ ) were purchased from VWR. The purification of the DNA-enzyme conjugate was carried out by Fast Protein Liquid Chromatography (FPLC) (GE Healthcare, Äkta Explorer) using a MonoQ 5/50 GL column.

\subsection{Synthesis of SsDNA conjugated with $\mathrm{GO}_{x}\left(\mathrm{D} 1-\mathrm{GO}_{x}\right)$}

For the synthesis of ssDNA conjugated with $\mathrm{GO}_{x}$, a procedure previously described (Fruk et al., 2007) was used. Experimental details are reported in Supplementary information.

\subsection{Fabrication, activation and functionalization of NEEs}

\subsubsection{Template fabrication of NEES}

NEEs were prepared by template gold electroless deposition, using a previously described procedure (De Leo et al., 2007). NEEs were then assembled as previously reported (Ugo and Moretto, 2007). Both procedures are described in Supplementary data.

\subsubsection{Characterization and activation of the PC membrane of NEEs}

The amount of $-\mathrm{COOH}$ groups present on the $\mathrm{PC}$ membrane of NEEs was measured by reacting the membrane with thionin acetate (THA) (Ivanov et al., 1996), as follows: a NEE was immersed into $800 \mu \mathrm{L}$ of a THA solution in ethanol (concentration $0.1 \mathrm{mg} \mathrm{mL}^{-1}$ ) and shaken overnight at room temperature in dark. The electrode was then removed, washed three times with ethanol and transferred into $800 \mu \mathrm{L}$ of a $0.01 \mathrm{~N} \mathrm{HCl}$ solution in a mixture ethanol/water $1: 1$. After shaking for $1.5 \mathrm{~h}$, the NEE was removed and a fluorescence spectrum of the final acidic solution was recorded (excitation wavelength: $594 \mathrm{~nm}$; emission wavelength: $620 \mathrm{~nm}$ ).

The number of $-\mathrm{COOH}$ groups present on the polymeric surface was increased by adapting the procedure proposed by Papra et al. (1999). Briefly, NEEs were immersed in $0.32 \mathrm{M} \mathrm{KMnO}_{4}, 0.75 \mathrm{~N}$ $\mathrm{H}_{2} \mathrm{SO}_{4}$ at RT for different times (90 and $150 \mathrm{~min}$ ), without shaking. 
Before the treatment, the insulating tape which surrounds the geometric area of each NEE was protected by a sacrificial layer of adhesive tape (which was removed after the treatment). Subsequently, the electrodes were rinsed with water and $3 \mathrm{M} \mathrm{HCl}$ in order to remove any oxidation residues (i.e., manganese oxide) from the polymeric surface, rinsed with water again, then ethanol and, finally, allowed to dry in air.

\subsubsection{Functionalization of NEEs}

Before proceeding with the immobilization of the oligonucleotide probes, the carboxylic groups were activated by immersion of NEEs into a $0.1 \mathrm{M}$ HEPES buffer solution ( $\mathrm{pH} 7.5$ ) containing $0.5 \mathrm{mM}$ EDC and $0.8 \mathrm{mM}$ sulfo-NHS. The incubation was allowed to proceed for 20 min under shaking (at RT). The addition of the succinimide derivative stabilizes the intermediate ester obtained by reaction between EDC and carboxylate groups (Staros et al., 1986), thus increasing the efficiency of the coupling reaction with the amino-ssDNA (acD1).

The functionalization was completed by transferring the electrodes into a 0.1 M HEPES buffer solution ( $\mathrm{pH} 7.5$ ) containing 400 pmoles of acD1 strands, incubated for $2 \mathrm{~h}$ under shaking, at $37^{\circ} \mathrm{C}$. The NEEs were finally rinsed with buffer.

In order to prevent any non-specific adsorption of the target ssD1 conjugated with $\mathrm{GO}_{x}\left(\mathrm{D} 1-\mathrm{GO}_{x}\right)$ on the activated polymeric surface, a blocking treatment was performed. The NEEs were immersed into a $20 \mathrm{mM}$ ethanolamine in $0.01 \mathrm{M}$ PBS solution ( $\mathrm{pH}$ 7.4). The reaction was allowed to proceed for $30 \mathrm{~min}$ at RT, under shaking. Ethanolamine is used to deactivate the remaining NHS-activated carboxylic groups (Park and Abbott, 2008) onto the polymeric membrane without interfering with biological macromolecules present on the surface of the NEE (Liberelle et al., 2010).

The hybridization reaction was carried out by spotting $10 \mu \mathrm{L}$ of a $0.01 \mathrm{M}$ PBS solution ( $\mathrm{pH} 7.4$ ) containing different amounts of D1- $\mathrm{GO}_{x}$ (from 2.5 to 20 pmoles) onto the capture DNA containing surfaces and incubating for $2 \mathrm{~h}$ at RT. Resulting DNA-modified NEEs were rinsed five times in $0.01 \mathrm{M}$ PBS over $10 \mathrm{~min}$, before being used for the electrochemical detection in the suitable electrolyte solution.

\section{Results and discussion}

\subsection{Characterization and functionalization of NEES}

At first, the PC surface of a NEE was characterized by spectrochemical titration with thionin acetate (see experimental) in order to estimate the amount of naturally occurring surface carboxylic groups available for the probe immobilization. The thionin procedure was used previously for the quantitative determination of carboxylic groups on activated polymers (Geismann and Ulbricht, 2005; Médard et al., 2001, 2002); it is based on the formation of ion pairs between the cationic dye and carboxylate moieties. A calibration curve was first obtained and subsequently employed for the quantification of the carboxylic groups. The obtained concentration of $-\mathrm{COOH}$ groups determined on the polymeric surface of the NEE was about $9.7 \times 10^{-10} \mathrm{~mol} \mathrm{~cm}^{-2}$.

These terminal functional groups of the polymeric chains present on the surface were then exploited for the immobilization of single stranded DNA (acD1) using EDC/NHS strategy (Staros et al., 1986) (Scheme 1a).

To enable the detection of the DNA hybridization event, thiolated complementary DNA (SHD1) was modified with glucose oxidase $\left(\mathrm{GO}_{x}\right)$ using sulfoSMCC methodology (Fruk et al., 2007) and subsequently hybridized to the capture acD1 immobilized on the PC (Scheme 1b). Glucose oxidase was chosen as the enzymatic label since it is readily available; moreover, the modification with single-stranded DNA is simple and it enables the amplification of the redox probe signal (Cass et al., 1984).

Electrochemical characterization of functionalized NEEs was performed in a deoxygenated PBS solution $(10 \mathrm{mM}, \mathrm{pH}=7.4)$ containing $0.1 \mathrm{mM} \mathrm{FA}^{+}$as the redox mediator. It should be noted that the solution was purged with nitrogen in order to prevent the eventual inhibition of $\mathrm{GO}_{x}$ enzymatic activity by $\mathrm{H}_{2} \mathrm{O}_{2}$, which is eventually produced by the competing reaction between the enzyme and the substrate, in presence of oxygen acting as an electron acceptor (Kleppe, 1966).

The full line voltammogram in Fig. 1a shows the CV behavior of $\mathrm{FA}^{+}$recorded using acD1 modified NEE, spotted with 20 pmoles of $\mathrm{D} 1-\mathrm{GO}_{x}$. The voltammetric pattern is reversible and diffusion controlled $\left(\Delta E_{p}=0.067 \mathrm{~V}, E_{1 / 2}=\left(E_{\mathrm{pa}}+E_{\mathrm{pc}}\right) / 2=0.42 \mathrm{~V}, I_{\mathrm{pc}} / I_{\mathrm{pa}}=1\right)$. In particular, the evidence that $I_{p}$ scales linearly with $v 1 / 2$ (data not shown), indicates that the functionalization of the NEE with the DNA probe does not interfere with the total overlap diffusive regime (Menon and Martin, 1995) which characterizes the $\mathrm{FA}^{+}$ voltammetric behavior at non-functionalized NEEs (Silvestrini et al., 2011). Note that the CV pattern recorded with a bare NEE (Fig. 1a, dotted line) overlap with the one recorded at the functionalized NEE, in the absence of the label substrate (Fig. 1a, full line). In the presence of $50 \mathrm{mM}$ glucose (Fig. 1a, dashed line), the voltammetric pattern, at the functionalized NEE, changes dramatically: the oxidation peak increases tending to a sigmoidal shape while the reduction peak disappears. The shape of the voltammogram is typical for an electrocatalytic process: in the presence of both enzyme label and the enzymatic substrate, the mediator is reduced chemically at the electrode/solution interface to be oxidized again directly at the electrode surface. Therefore, the above described voltammetric evidences indicate that the functionalization with the capture probe and the subsequent hybridization with the $\mathrm{GO}_{x}$ labeled target on the NEE are successful. Moreover, it is demonstrated that $\mathrm{GO}_{x}$ acts as a sensitive and efficient label, suitable to detect the hybridization event at the NEE. Fig. 1b shows that a well detectable electrocatalytic current increase is observed also when the target amount is lowered to 2.5 picomoles.

Data reported in Fig. 2 show the change in electrocatalytic current as a function of the amount of target spotted on the sensor. A linear trend is observed with a sensitivity of 25 $\mathrm{nA} /$ pmoles. Repeated measurements performed on three different

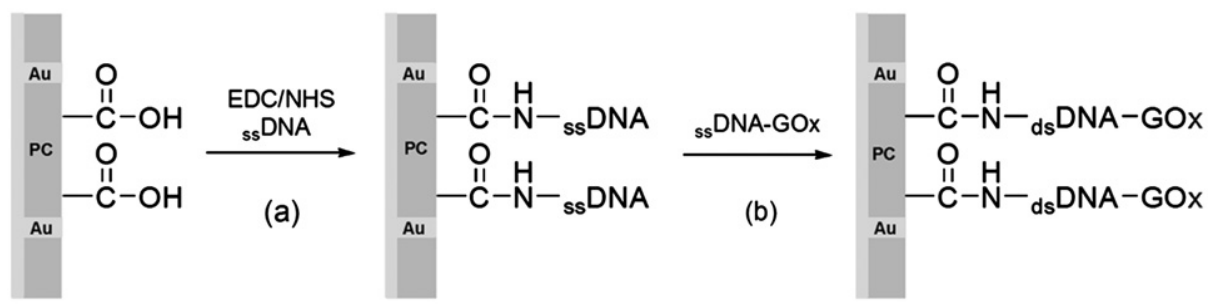

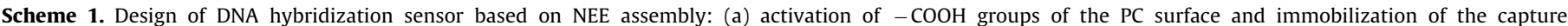
complementary acD1 onto the activated carboxylic functionalities and (b) hybridization of DNA-GO ${ }_{x}$ conjugate onto modified PC surface. 


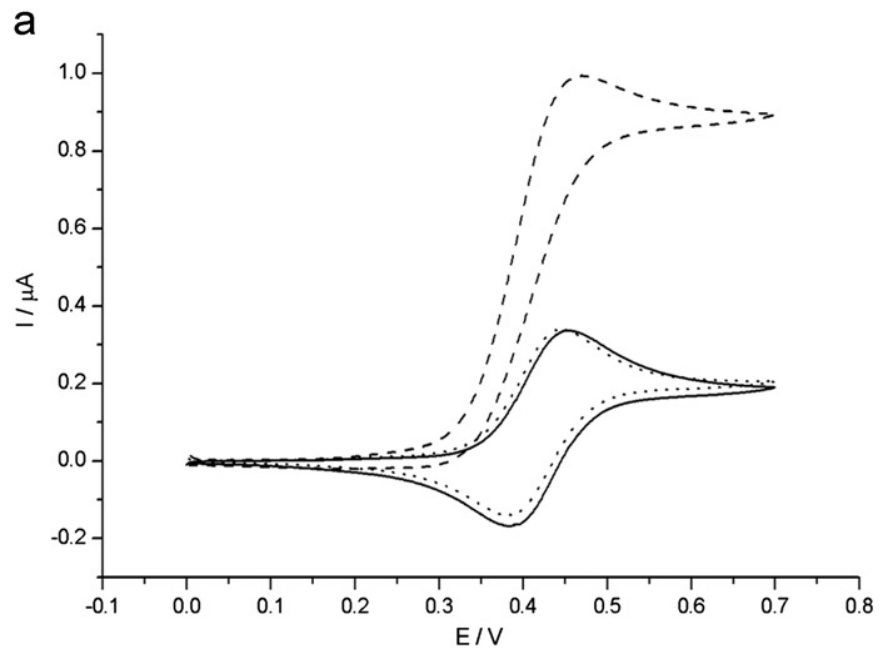

b

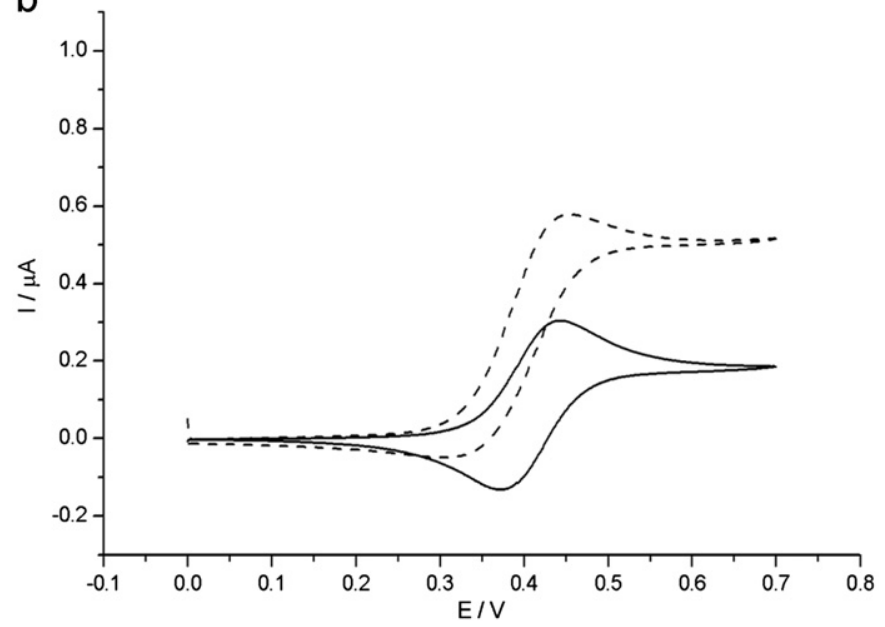

Fig. 1. Cyclic voltammograms recorded with NEEs functionalized with acD1 and treated with either (a) 20 pmoles or (b) 2.5 pmoles $\mathrm{D} 1-\mathrm{GO}_{x}$ in a $10 \mathrm{mM}$ PBS solution $(\mathrm{pH}=7.4)$ containing $0.1 \mathrm{mM} \mathrm{FA}^{+} \mathrm{PF}_{6}^{-}$before (full line) and after (dashed line) the addition of $50 \mathrm{mM}$ glucose. Control in which bare NEE is used is represented by the dotted line (a). Scan rate $5 \mathrm{mV} \mathrm{s}^{-1}$.

NEEs indicated that the standard deviation $(\sigma)$ measured on $\Delta I_{\text {cat }}$ (where $\Delta I_{\text {cat }}=I_{\text {cat }}$ in the presence of glucose- $I_{\text {peak }}$ in the absence of glucose) is $1 \mathrm{nA}$. This value indicates a very good precision for the detection; interestingly, this $\sigma$ value is 10 times smaller than the standard deviation (namely, $10 \mathrm{nA}$ ) measured on three different NEEs, functionalized as above described, for the $\mathrm{FA}^{+}$signal alone. This suggests that the electrocatalytic current increase (which in our conditions is proportional to the amount of $\mathrm{GO}_{x}$ label immobilized on the PC surface of the NEE) is less sensitive to the variability in the NEE fabrication procedure than the peak current measured for redox probes under pure diffusion control (Pereira et al., 2006). The minimum detectable amount of target DNA, based on the $3 \sigma$ criterion, was estimated 0.1 pmoles.

Fig. 3 shows the CVs recorded with non-functionalized NEEs when mediator $(0.1 \mathrm{mM})$, substrate $(50 \mathrm{mM})$ and $5 \mathrm{nM}$ (20 pmoles) unmodified $\mathrm{GO}_{x}$ (Fig. 3a, $0.42 \mu \mathrm{A}$ ) or $5 \mathrm{nM}$ (20 pmoles) D1-GO (Fig. $3 \mathrm{~b}, 0.55 \mu \mathrm{A}$ ) are present in the solution. Comparison with Fig. 1a indicates that the anodic current value measured with the DNA functionalized NEE in the presence of the glucose is significantly higher than the current values detected with the bare NEE.

It is worth stressing that, in order to achieve a comparable catalytic current value as in Fig. $1 \mathrm{a}$, the amount of $\mathrm{GO}_{x}$ in solution, in experiments like those in Fig. 3a, must be increased up to

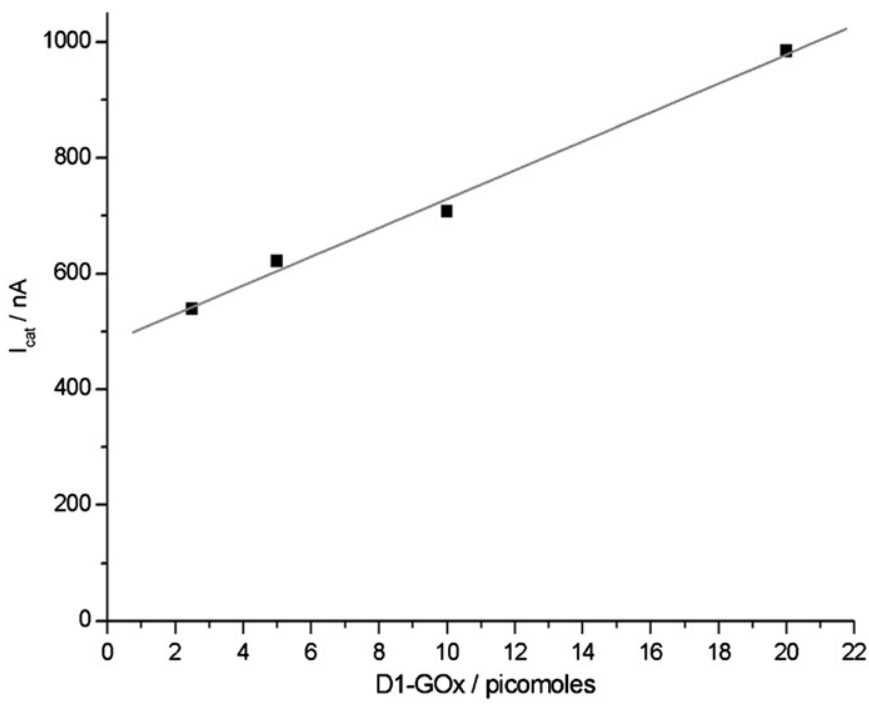

Fig. 2. $I_{\text {cat }}$ values recorded with NEEs functionalized with acD1 and treated with different amounts of $\mathrm{D} 1-\mathrm{GO}_{x}(2.5 ; 5 ; 10 ; 20$ pmoles $)$, in a $10 \mathrm{mM}$ PBS solution $(\mathrm{pH}=7.4)$ containing $0.1 \mathrm{mM} \mathrm{FA}^{+} \mathrm{PF}_{6}^{-}$. Scan rate $5 \mathrm{mV} \mathrm{s}^{-1}$.
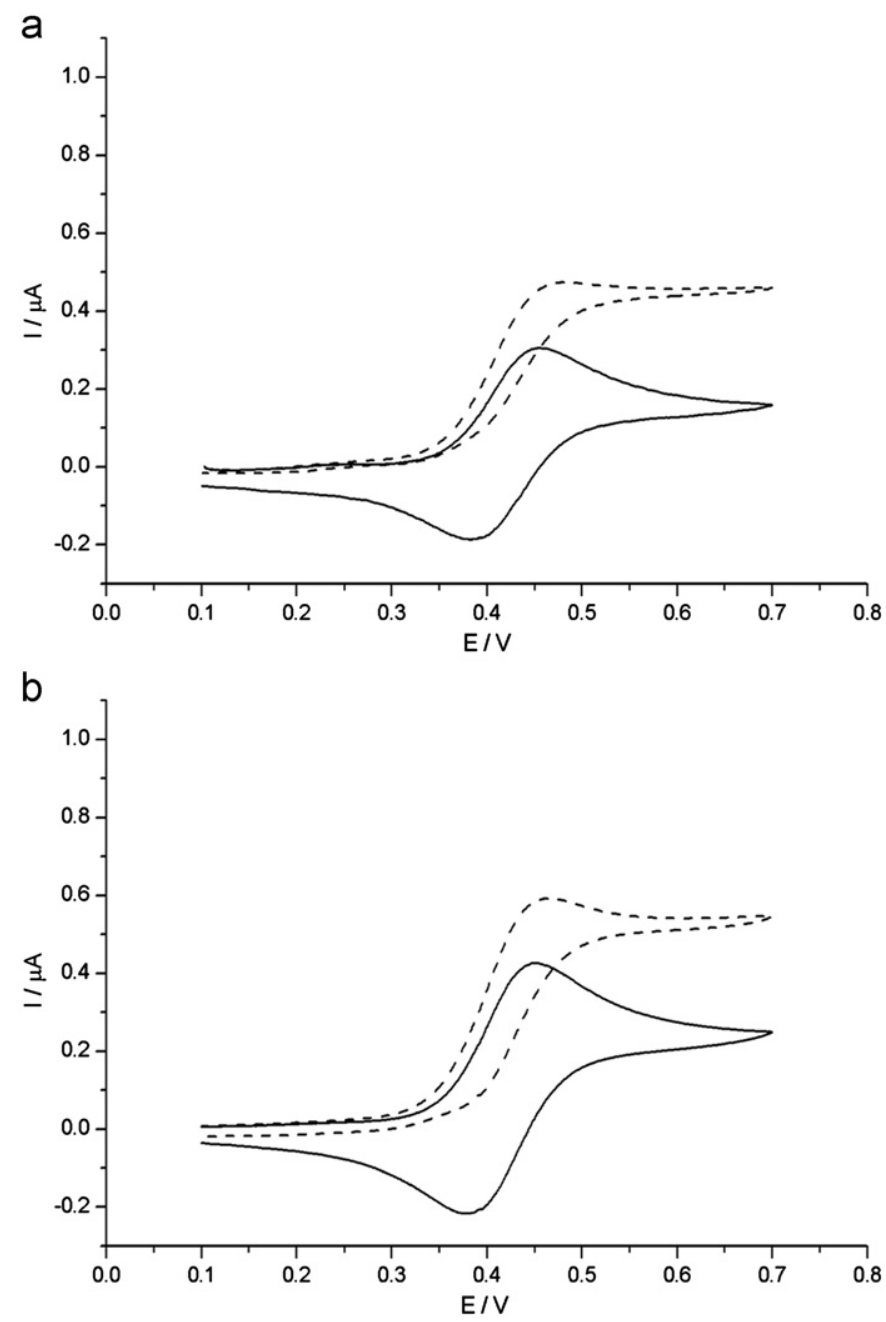

Fig. 3. Cyclic voltammograms recorded with a bare NEE in a $10 \mathrm{mM}$ PBS solution $(\mathrm{pH}=7.4)$ containing $0.1 \mathrm{mM} \mathrm{FA}^{+} \mathrm{PF}_{6}^{-}$and $50 \mathrm{mM}$ glucose before (full line) and after (dashed line) the addition to the electrolyte solution of (a) 20 pmoles $\mathrm{GO}_{x}$ and (b) 20 pmoles $\mathrm{D} 1-\mathrm{GO}_{x}$. Scan rate $5 \mathrm{mV} \mathrm{s}^{-1}$. 
200 pmoles. These results confirm the high capture efficiency of D1-GO ${ }_{x}$ by the acD1 functionalized NEE. Control experiments using non-complementary capture DNA (acD2) and D1-GO ${ }_{x}$ did not show any significant electrochemical activity (Fig. S1, Supplementary data) and confirmed that non-specific adsorption of the labeled target is negligible.

These results indicate a good detection capability for the functionalized NEEs with detection limits below the picomoles.

\subsection{Effect of the chemical activation of NEES}

In order to further increase the detection performances demonstrated above, we tested the possibility of increasing the surface concentration of $-\mathrm{COOH}$ groups on the PC surface and, consequently, the amount of probe which can be bound, by treatment with $\mathrm{KMNO}_{4}$ as described in earlier reports (Papra et al., 1999; Thorp et al., 1999). The number of generated carboxylic groups was again determined by fluorescence labeling using thionin acetate (THA). The fluorescence intensities of the acidic solutions containing THA and the relative calculated amounts of $-\mathrm{COOH}$ per $\mathrm{cm}^{2}$, obtained after 90 and $150 \mathrm{~min}$ of oxidative treatment of the NEEs with $\mathrm{KMnO}_{4}$, are listed in Table 1 and compared with those measured for the non-activated NEE.

These data show a significant increase in surface $-\mathrm{COOH}$ concentration upon $\mathrm{KMnO}_{4}$ activation; for instance, a $150 \mathrm{~min}$ treatment leads to a three-fold increase in the surface concentration of carboxylic groups.

These activated electrodes were then functionalized with the acD1 capture probe and hybridized with the $\mathrm{D} 1-\mathrm{GO}_{x}$ target using the same procedure as described for non activated NEEs. Fig. 4 shows the voltammetric responses recorded in $\mathrm{FA}^{+}$solution with activated NEE (90 min) to which $\mathrm{D} 1-\mathrm{GO}_{x}$ was immobilized, before and after the addition of the excess glucose (full and dashed lines, respectively). The voltammetric signal of the mediator recorded before the glucose addition differs from the one reported in Fig. 1a, mainly for the larger capacitive current which is evident between 0.0 and $0.2 \mathrm{~V}$, i.e., before the rising of the Faradaic signal (CV peaks). After adding excess glucose, the Faradaic anodic current increases up to $1.24 \mu \mathrm{A}$ and the peak tends to a sigmoidal shape, while the associated cathodic peak (return scan) disappears. All these features are comparable to those observed for the DNA-GO ${ }_{x}$ on non-activated NEE, apart the significant increase in the double-layer (background) charging current. Note that the $\Delta I_{\text {cat }}$ value (difference in anodic peak current with and without glucose) is now slightly higher being $0.8 \mu \mathrm{A}$ at the $\mathrm{KMnO}_{4}$-activated (Fig. 4) and $0.64 \mu \mathrm{A}$ at non-activated (Fig. 1a). NEE. Control experiments (data not shown) again showed that there is no significant non-specific adsorption of the DNA-GO $\mathrm{G}_{x}$ target at the activated NEE.

The above results indicate that both the functionalization with the capture DNA probe and the hybridization with the $\mathrm{GO}_{x}$ labeled target can be performed successfully using $\mathrm{KMnO}_{4}$ activated NEEs. Furthermore, the amount of DNA captured by the activated electrode is slightly higher than in the case when there is no prior treatment, as indicated by the $15-20 \%$ Faradaic current increase for the activated vs. non-activated NEE. However, the activation of the NEE with $\mathrm{KMnO}_{4}$ causes an undesired increase in the background current.

Table 1

Concentration of $-\mathrm{COOH}$ groups measured by the thionin acetate method, after activation of the PC surface with the $\mathrm{KMnO}_{4}$ for the indicated time.

\begin{tabular}{|c|c|c|}
\hline $\begin{array}{l}\text { Time of treatment with } \\
\mathrm{KMnO}_{4} \text { (min) }\end{array}$ & $\begin{array}{l}\text { Intensity } \\
\text { (a.u.) }\end{array}$ & $\begin{array}{l}\text { Concentration of } \mathrm{COOH} \text { groups } \\
\left(\mathrm{mol} \mathrm{cm}^{-2}\right)\end{array}$ \\
\hline 0 & 7.7 & $\sim 9.7 \times 10^{-10}$ \\
\hline 90 & 21.1 & $\sim 2.7 \times 10^{-9}$ \\
\hline 150 & 26.9 & $\sim 3.4 \times 10^{-9}$ \\
\hline
\end{tabular}

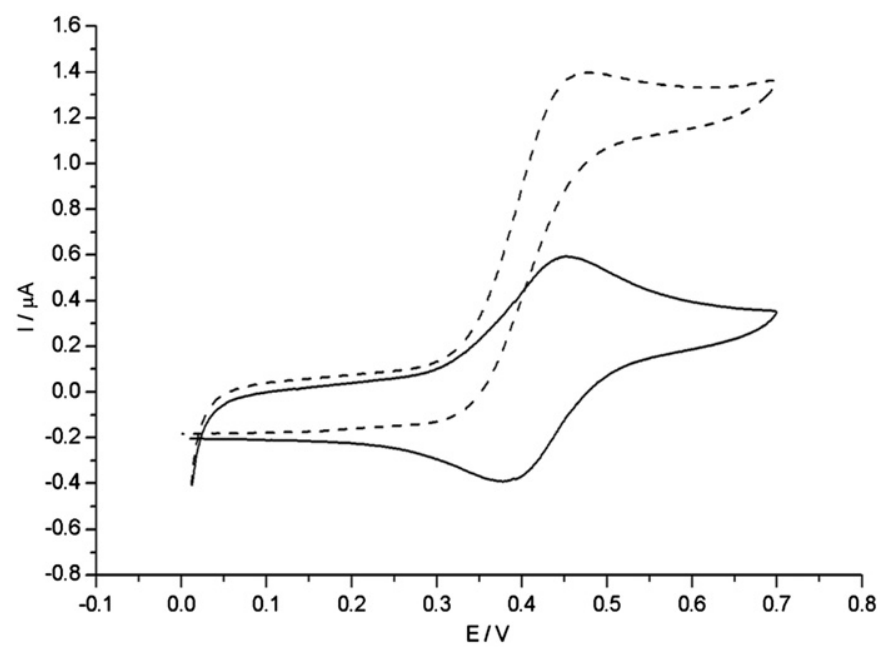

Fig. 4. Cyclic voltammograms recorded with a NEE activated with $\mathrm{KMnO}_{4}$, functionalized with acD1 and treated with 20 pmoles of functionalized D1-GO, Measurements were performed in a $10 \mathrm{mM}$ PBS solution $(\mathrm{pH}=7.4)$ containing $0.1 \mathrm{mM} \mathrm{FA}^{+} \mathrm{PF}_{6}^{-}$before (full line) and after (dashed line) the addition of $50 \mathrm{mM}$ glucose. Scan rate $5 \mathrm{mV} \mathrm{s}^{-1}$.

Table 2

Active area values of NEEs after treatment with $\mathrm{KMnO}_{4}$, as a function of the oxidation time.

\begin{tabular}{cl}
\hline $\begin{array}{l}\text { Time of treatment } \\
\text { with } \mathrm{KMnO}_{\mathbf{4}} \text { ( min) }\end{array}$ & $\boldsymbol{A}_{\text {act }}\left(\mathbf{c m}^{\mathbf{2}}\right)$ \\
\hline 0 & \\
\hline 90 & $3.2 \times 10^{-3}$ \\
150 & $3.7 \times 10^{-2}$ \\
\hline
\end{tabular}

In order to investigate the latter effect, a series of background CVs were recorded at bare NEEs in pure supporting electrolyte $\left(0.01 \mathrm{M} \mathrm{KNO}_{3}\right)$, before and after the chemical activation (Fig. S2, Supplementary data); $A_{\text {act }}$ values were obtained by relevant capacitive current values (Menon and Martin, 1995); relevant results are summarized in Table 2 .

The $A_{\text {act }}$ values scale with the time length of the $\mathrm{KMnO}_{4}$ treatment. This can be due either to the partial etching of the outer layer of the polymer and/or the loss in sealing between the Au nanofibers and the surrounding membrane. Both these conditions could cause a partial exposure of the fibers, increasing the area of the metal surface in contact with the solution (De Leo et al., 2007). SEM observations (not shown) confirmed this hypothesis, showing that after, e.g., 90 min oxidation with $\mathrm{KMnO}_{4}$, the tips of the nanoelectrodes emerged from the PC substrate for approximately $80-100 \mathrm{~nm}$. Moreover, some slits were formed at the junction between the gold nanofibers and PC, so producing a final morphology similar to that of the 3DNEEs previously obtained by chemical etching of NEEs with ethanol-dichloromethane (De Leo et al., 2007).

From the data obtained we can conclude that the activation treatment increases the sensitivity of about $20 \%$; however, this procedure also causes an increase in the background current and requires a more complex functionalization procedure.

\section{Conclusions}

We have, for the first time, shown that the polymer surface of nanoelectrode ensembles can be bio-functionalized with DNA, by utilizing the amide coupling strategy to immobilize single-stranded 
DNA onto the PC, instead that onto the gold electrode surface (Gasparac et al., 2004). Electrochemical detection of hybridization with complementary strand containing a reporter enzyme $\mathrm{GO}_{x}$ and with the help of a redox mediator, results effective and sensitive allowing one to detect few pmoles of target DNA. The oxidation of the polymer surface by permanganate can be used to increase the number of $-\mathrm{COOH}$ groups present on the PC; however, this reflects in an increase in the capacitive current, due to the partial etching of the PC. Detection capabilities of non-oxidized NEEs are surely attractive, however with the notation that when larger amounts of target DNA need to be captured, the activation of PC can be used. Further studies on the long term stability for the sensor as well as on the possibility to improve detection capabilities by using pulsed voltammetric techniques are in progress.

\section{Acknowledgements}

This work was supported by KIT Excellence Initiative 20062011, grant A5.7, by MIUR (Rome), project: PRIN 2008MWHCP2 and by the Cross-Border Cooperation Italy-Slovenia Programme 2007-2013-Strategic Project TRANS2CARE.

\section{Appendix A. Supplementary information}

Supplementary data associated with this article can be found in the online version at http://dx.doi.org/10.1016/j.bios.2012.07.041.

\section{References}

Abdullin, T.I., Nikitina, I.I., Ishmukhametova, D.G., Budnikov, G.K., Konovalova, O.A., Salakhov, M.K., 2007. Journal of Analytical Chemistry 62, 599-603.

Brunetti, B., Ugo, P., Moretto, L.M., Martin, C.R., 2000. Journal of Electroanalytical Chemistry 491, 166-174.

Carpini, G., Lucarelli, F., Marrazza, G., Mascini, M., 2004. Biosensors and Bioelectronics 20, 167-175.

Cass, A.E.G., Davis, G., Francis, G.D., Hill, H.A.O., Aston, W.J., Higgins, I.J., Plotkin, E.V., Scott, L.D.L., Turner, A.P.F., 1984. Analytical Chemistry 56, 667-671.

De Leo, M., Kuhn, A., Ugo, P., 2007. Electroanalysis 19, 227-236.

De Leo, M., Pereira, F.C., Moretto, L.M., Scopece, P., Polizzi, S., Ugo, P., 2007. Chemistry of Materials 19, 5955-5964.

Fruk, Lj., Müller, J., Weber, G., Narvaez, A., Dominguez, E., Niemeyer, C.M., 2007. Chemistry A European Journal 13 (18), 5223-5231.

Gasparac, R., Taft, B.J., Lapierre-Devlin, M.A., Lazareck, A.D., Xu, J.M., Kelley, S.O., 2004. Journal of the American Chemical Society 126, 12270-12271.

Geismann, C., Ulbricht, M., 2005. Macromolecular Chemistry and Physics 206, 268-281.
Girousi, S., Kinigopoulou, V., 2010. Central European Journal of Chemistry 8 $732-736$

Hvastkovs, E.G., Buttry., D.A., 2010. Analyst 135, 1817-1829.

Ivanov, V.B., Behnisch, J., Holländer, A., Mehdorn, F., Zimmermann, H., 1996 Surface and Interface Analysis 24, 257-262.

Kerman, K., Kobayashi, M., Tamiya, E., 2004. Measurement Science and Technology 15, R1-R11.

Kerman, K., Morita, Y., Takamura, Y., Tamiya, E., 2003. Electrochemistry Communications 5, 887-891.

Kleppe, K., 1966. Biochemistry 5, 139-143.

Krishnamoorthy, K., Zoski, C.G., 2005. Analytical Chemistry 77, 5068-5071.

Lapierre-Devlin, M.A., Asher, C.L., Taft, B.J., Gasparac, R., Roberts, M.A., Kelley, S.O., 2005. Nano Letters 5 (6), 1051-1055.

Levine, P.M., Gong, P., Levicky, R., Shepard, K.L., 2009. Biosensors and Bioelectronics 24, 1995-2001.

Li, J., Tee, Ng H., Cassell, A., Fan, W., Chen, H., Ye, Q., Koehne, J., Han, J., Meyyappan, M., 2003. Nano Letters 3, 597-602.

Li, Y., Wang, Z., Ou, L.M.L., Yu, H.-Z., 2007. Analytical Chemistry 79, 426-433.

Liberelle, B., Boucher, C., Chen, J., Jolicoeur, M., Durocher, Y., De Crescenzo, G. 2010. Bioconjugate Chemistry 21, 2257-2266.

Lombardo, A., Bieber, T.I., 1983. Journal of Chemical Education 60, 1080-1081.

Lucarelli, F., Marrazza, G., Turner, A.P., Mascini, M., 2004. Biosensors and Bioelectronics $19,515-530$.

Médard, N., Aouinti, M., Poncin-Epaillard, F., Bertrand, P., 2001. Surface and Interface Analysis 31, 1042-1047.

Médard, N., Soutif, J.-C., Poncin-Epaillard, F., 2002. Surface and Coatings Technology 160, 197-205.

Menon, V.P., Martin, C.R., 1995. Analytical Chemistry 67, 1920-1928.

Morais, S., Marco-Molés, R., Puchades, R., Maquieira, A., 2006. Chemical Communications, 2368-2370.

Morais, S., Tortajada-Genaro, L.A., Arnandis-Chover, T., Puchades, R., Maquieira, A. 2009. Analytical Chemistry 81, 5646-5654.

Moretto, L.M., Tormen, M., De Leo, M., Carpentiero, A., Ugo, P., 2011. Nanotechnology $22,185305-185312$.

Mucelli, S.P., Zamuner, M., Tormen, M., Stanta, G., Ugo, P., 2008. Biosensors and Bioelectronics 23, 1900-1903.

Papra, A., Hicke, H.-G., Paul, D., 1999. Journal of Applied Polymer Science 74, 1669-1674.

Park, J.-S., Abbott, N.L., 2008. Advanced Materials 20, 1185-1190.

Pedrero, M., Campuzano, S., Pingarrón, J.M., 2011. Analytical Methods 3, 780-789.

Pereira, F.C., Moretto, L.M., De Leo, M., Bodrin Zanoni, M.V., Ugo, P., 2006. Analytica Chimica Acta 575, 16-24.

Rucker, V.C., Havenstrite, K.L., Simmons, B.A., Sickafoose, S.M., Herr, A.E., Shediac, R., 2005. Langmuir 21, 7621-7625.

Silvestrini, M., Schiavuta, P., Scopece, P., Pecchielan, G., Moretto, L.M., Ugo, P., 2011 Electrochimica Acta 56, 7718-7724.

Staros, J.V., Wright, R.W., Swingle, D.M., 1986. Analytical Biochemistry 156 220-222.

Tang, L., Zeng, G., Shen, G., Li, Y., Liu, C., Li, Z., Luo, J., Fan, C., Yang, C., 2009. Biosensors and Bioelectronics 24, 1474-1479.

Thorp, H.H., Loomis, C.R., Napier, M.E., 1999. Patent No. US5968745.

Ugo, P., Moretto, L.M., Bellomi, S., Menon, V.P., Martin, C.R., 1996. Analytical Chemistry 68, 4160-4165.

Ugo, P., Moretto, L.M., 2007. Template deposition of metals. In: Zoski, C.G. (Ed.), Handbook of Electrochemistry. Elsevier, Amsterdam, pp. 678-709.

Wang, Z., Li, R.-X., 2007. Nanoscale Research Letters 2, 69-74.

Wei, M.-Y., Guo, L.-H., Famouri, P., 2011. Microchimica Acta 172, 247-260.

Yu, S., Li, N., Wharton, J., Martin, C.R., 2003. Nano Letters 3, 815-818. 